\title{
Correlation between grain quality of foxtail millet (Setaria italica [L.] P. Beauv.) and environmental factors on multivariate statistical analysis
}

\author{
Na Ning ${ }^{1}$, Yan-jun Yang ${ }^{2}$, Jian-ping Hong ${ }^{1}$, Xiang-yang Yuan ${ }^{3 *}, X_{i}-e S^{\prime} o n{ }^{3}$, \\ Hong-fu Wang ${ }^{3}$, and Ping-yi Guo ${ }^{3}$
}

\section{ABSTRACT}

Quantifying the effects of environmental conditions on grain quality of foxtail millet (Setaria italica [L.] P. Beauv.) is critical for large-scale promotion of high-quality foxtail millet according to local conditions. We analyzed quantitative correlation between grain quality of foxtail millet and environmental factors during the growing season (May-September) using multivariate statistical analysis under different ecological conditions at five representative locations across Shanxi Province, China. Based on the results of principal component analysis, the first principal component, which explained $58.22 \%$ of total variance in grain quality, was selected to represent the comprehensive quality of foxtail millet. The results of gray relational analysis showed that the difference in grain quality across different locations was mainly affected by altitude (grey relational grade $[\mathrm{GRG}]=0.8137$ ), followed by precipitation $(\mathrm{GRG}=0.7744)$, diurnal temperature range $(\mathrm{GRG}=0.6816)$, latitude $(\mathrm{GRG}=0.5417)$, sunshine hours $(\mathrm{GRG}=0.5052)$, and $\geq 20{ }^{\circ} \mathrm{C}$ accumulated temperature $(\mathrm{GRG}=0.4517)$. The precipitation of July and diurnal temperature range of July-September had the greatest effect on grain quality of foxtail millet. Stepwise regression and path analyses revealed that altitude, precipitation, and $\geq 20$ ${ }^{\circ} \mathrm{C}$ accumulated temperature were the major environmental factors affecting grain quality of foxtail millet, which determined $99 \%$ of total variance in grain quality. Altitude and precipitation exhibited a significant positive effect, while $\geq 20{ }^{\circ} \mathrm{C}$ accumulated temperature showed a significant negative effect. The regression equation proposed in this study $\left(P=0.0048, \mathrm{R}^{2}=0.99\right)$ can be used to predict and forecast grain quality of foxtail millet.

Key words: Environmental factors, foxtail millet grain quality, gray relational analysis, path analysis, principal component analysis, stepwise regression.

${ }^{1}$ Shanxi Agricultural University, College of Resources and Environment, Taigu 030801, China.

${ }^{2}$ Jinzhong University, College of Biology and Technology, Yuci 030600, China.

${ }^{3}$ Shanxi Agricultural University, College of Agriculture, Taigu 030801, China. "Corresponding author (yuanxiangyang200@163.com).

Received: 3 July 2017.

Accepted: 16 October 2017

doi:10.4067/S0718-58392017000400303

\section{INTRODUCTION}

Foxtail millet (Setaria italica [L.] P. Beauv.), an important annual gramineae cereal food crop with good nutritional value, was originated from North China (Jones and Liu, 2009; Yang et al., 2012; Ning et al., 2016). Due to its better adaptability to barren and arid lands than other crops, foxtail millet plays an important role in agricultural production in arid and semi-arid regions of the world (Veeranagamallaiah et al., 2008). Because of its small diploid genomes, short life cycles, self-pollination, small adult height and prolific seed production, domesticated foxtail millet is being promoted as a novel model species for functional genomics of the grass crop, especially for study of $\mathrm{C} 4$ photosynthesis (Diao et al., 2014; Muthamilarasan and Prasad, 2015).

North China - especially Shanxi Province - is one of the largest production regions of foxtail millet in China. This area, which extends from $34^{\circ} 36^{\prime} \mathrm{N}$ to $40^{\circ} 44^{\prime} \mathrm{N}, 110^{\circ} 15^{\prime} \mathrm{E}$ to $114^{\circ} 32^{\prime}$ E, accounts for $29.35 \%$ of the cultivated foxtail millet area in China and produced approximately $21.05 \%$ of total foxtail millet grain in China. Since more than $90 \%$ of the world's foxtail millet is cultivated in China, Shanxi Province plays a significant role in ensuring food security (National Bureau of Statistics of China, 2013). With an altitude of 180-3058 $\mathrm{m}$, the climate varies substantially. Annual accumulated temperatures above $10{ }^{\circ} \mathrm{C}$, sunshine hours, and precipitation range from 2251.6 to $4636.2^{\circ} \mathrm{C}$, 2070.8 to $2973.67 \mathrm{~h}$, and 362.4 to $606.5 \mathrm{~mm}$, respectively (Qian and $\mathrm{Hu}, 2008$; Hao et al., 2009).

Variations in climate and ecological resource lead to variations in foxtail millet grain quality. Latitude, altitude, and hours of sunshine during the growing season were found to be significantly correlated with foxtail millet protein content (He et al., 1985). Li (1987) reported a negative relationship between foxtail millet fat content and accumulated temperature. Zhao et al. (2002) found growth period, precipitation, and altitude were strongly associated with foxtail millet amylase content. Although some papers have reported the effects of environmental factors on crop quality in wheat (Bornhofen et al., 2017), maize (Farrell and Gilliland, 2011; Lu et al., 2016), rice (Donoso-Ñanculao et al., 2016; Chen et al., 2017), pearl millet (Ullah et al., 2017) and oats (Marketta, 2008), little work has focused on the impact of environment on foxtail millet. Moreover, existing studies have focused on the relationship between individual quality indicators of foxtail millet and individual environmental conditions in single ecological regions of limited spatial scope. These studies have commonly used 
individual statistical methods (e.g., simple correlation analysis) and lacked comprehensiveness (He et al., 1985; Li, 1987; Zhao et al., 2002).

Principal component analysis (PCA) is a statistical technique that has been widely applied to a set of variables to reduce their dimensionality. PCA is used to extract a smaller number of independent factors (principal components) from a large set of intercorrelated variables, starting with the correlation matrix describing the dispersion of original variables and extracting the eigenvalues and eigenvectors (Anju and Banerjee, 2012). Gray relational analysis (GRA) takes numerous factors as gray systems and reflects the importance of each factor by ranking the gray relational grade (GRG). The greatest advantage of GRA is that it eliminates the subjectivity and extensiveness, and thus fully reveals the importance of each factor (Huang, 2011). Although GRA can explain the importance of different environmental factors to grain quality of foxtail millet, it cannot reveal the relationship of internal regulation.

Furthermore, multivariate stepwise regression analysis (SRA) has been used to clarify the real regulatory role of different environmental factors on grain quality of foxtail millet. The advantage of SRA is that it introduces independent variables based on the significance of their effect on the dependent variable (from high to low), until there are no nonsignificant independent variables to be removed from the regression equation $(P>0.01)$ and nonsignificant variables to be introduced $(P<0.05)$. The optimal regression equation is therefore established for quantitative analysis of the effect of various factors (Adrian, 2012). However, when analyzing multiple variables that interact with each other and have different units of measure, the regression coefficient does not reflect the degree to which the independent variables affect the outcome variable. In this case, path analysis (PA) can be used as a supplementary method to further uncover the direct and indirect effects of major influencing factors and clarify how the independent variables directly affect the dependent variable or indirectly affect it through other independent variables (Mostafa et al., 2011). A combination of the above four methods will further clarify and quantify the effects of environmental factors on grain quality of foxtail millet, which has implications for largescale promotion of high-quality foxtail millet according to local conditions.

The present study was therefore carried out to (1) investigate the difference in grain quality of foxtail millet at five different locations across Shanxi Province, China, by comprehensive analysis of multiple indicators, (2) establish the quantitative relationship between grain quality of foxtail millet and multiple environmental factors at these locations during the growing season based on a progressive, cascading multivariate statistical analysis, and (3) identify the key factors for grain quality of foxtail millet and described their effects.

\section{MATERIALS AND METHODS}

\section{Experimental sites}

Experiments were conducted at five locations (south to north: Gaoping, Qinxian, Fenyang, Fuci, and Fanshi) in Shanxi Province in the north foxtail millet region of China. Tables 1 and 2 list the geographical positions and meteorological conditions of the experimental sites, respectively. Longitude, latitude, and altitude at each location were accurately measured using GPS. We obtained climate data including sunshine hours, precipitation, $\geq 20{ }^{\circ} \mathrm{C}$ accumulated temperature, and diurnal temperature range for the experimental locations during the growing season of foxtail millet (May-September) in 2013 from the Shanxi Meteorological Bureau.

\section{Plant material}

The foxtail millet variety used in the experiment was a high-yield and high-quality cultivar, 'Changnong 35'. This cultivar is grown widely in North China. Seeds were obtained from the Millet Research Institute of Agricultural Sciences of Shanxi Province (Changzhi, Shanxi, China).

\section{Sampling strategy}

At all sites, foxtail millet seeds were sown (giving a density of $\sim 300000$ plants $\mathrm{ha}^{-1}$ ) by unified seeding machine from the end of May to the beginning of June and harvested from the end of September to the beginning of October in 2013. Samples for grain were obtained from each site by hand harvesting the central $5 \mathrm{~m}^{2}$ areas to avoid border effects. The samples were dehulled twice using a rice dehuller (JLGJ4.5, Taizhou Food Instrument Factory, Zhejiang, China). The dehulled samples were dried at $60{ }^{\circ} \mathrm{C}$ for $48 \mathrm{~h}$, ground mechanically (DFY-500A, Bilon, China), and passed through a $0.5-\mathrm{mm}$ sieve. The sieved samples were stored in a desiccator before nutrient analysis. All experimental sites were well managed and weeds, diseases, and insect pests were well controlled.

Table 1. Geography positions of the experimental sites.

\begin{tabular}{lccc}
\hline Collection sites & Altitude $(\mathrm{m}$ a.s.1.) & Longitude $\left(^{\circ}\right)$ & Latitude $\left(^{\circ}\right)$ \\
\hline Gaoping & 850.50 & 112.89 & 35.83 \\
Qinxian & 1013.00 & 112.68 & 36.74 \\
Fenyang & 743.00 & 111.79 & 37.26 \\
Yuci & 801.50 & 112.72 & 37.61 \\
Fanshi & 1151.80 & 113.69 & 39.30 \\
\hline
\end{tabular}

Table 2. Meteorological data of the experimental sites during growing season of foxtail millet (May-September).

\begin{tabular}{lcccc}
\hline $\begin{array}{l}\text { Collection } \\
\text { sites }\end{array}$ & Precipitation & $\begin{array}{c}\geq 20{ }^{\circ} \mathrm{C} \\
\text { accumulated } \\
\text { temperature }\end{array}$ & $\begin{array}{c}\text { Sunshine } \\
\text { hours }\end{array}$ & $\begin{array}{c}\text { Diurnal } \\
\text { temperature } \\
\text { range }\end{array}$ \\
\hline Gaoping & $\mathrm{mm}$ & ${ }^{\circ} \mathrm{C}$ & $\mathrm{h}$ & ${ }^{\circ} \mathrm{C}$ \\
Qinxian & 561.20 & 2741.50 & 1021.40 & 12.16 \\
Fenyang & 623.70 & 2215.00 & 926.30 & 12.92 \\
Yuci & 495.30 & 2767.50 & 985.10 & 12.70 \\
Fanshi & 453.50 & 2758.50 & 1094.70 & 12.23 \\
\hline
\end{tabular}




\section{Chemical analysis}

The crude protein and fat content of grain samples were determined by the Association of Official Analytical Chemists methods (AOAC, 2000). Percentage crude protein $(\% \mathrm{CP})$ was determined by the Kjeldahl method and calculated based on the percentage $\mathrm{N}(\% \mathrm{~N})$ obtained: $\%$ $\mathrm{CP}=\% \mathrm{~N} \times 6.25$. Fat content $(\%)$ was determined using the Soxhlet extraction technique.

The gel consistency was determined using a method described by Tran et al. (2011) with slight modifications. Finely ground foxtail millet grain $(100 \mathrm{mg})$ was weighed in duplicate into $13 \mathrm{~mm} \times 100 \mathrm{~mm}$ tubes and $200 \mu \mathrm{L}$ ethyl alcohol (95\%), containing $0.025 \%$ thymol blue, was added to each tube as well as $2.5 \mathrm{~mL} 0.15 \mathrm{~N} \mathrm{KOH}$. Tubes were mixed using a Vortex Genie mixer, then placed in a vigorously boiling water bath for $8 \mathrm{~min}$. The tubes were removed from the water bath, held at room temperature for $5 \mathrm{~min}$, and cooled in an ice water bath for $20 \mathrm{~min}$. Following this, tubes were laid horizontally on a light box on top of graphing paper. After $1 \mathrm{~h}$, the distance the gel migrated in the tube was measured.

The amylose content in foxtail millet starches was determined according to the procedure of the American Association of Cereal Chemists (2000).

The alkali digestion value was measured with twenty intact and fully mature foxtail millet grains of uniform size were placed in a Petri dish. Exactly $10 \mathrm{~mL} 1.7 \%$ potassium hydroxide solution was added to each Petri dish until the grains were completely submerged. The grains remained dispersed to facilitate decomposition and covered with a lid. The samples were placed in a $30{ }^{\circ} \mathrm{C}$ thermostat incubator for $6 \mathrm{~h}$ and the decomposition of each grain was then observed. The degree of decomposition was recorded according to Table 3 . The alkali digestion value was calculated as follows:

$$
A=\sum(\mathrm{G} * \mathrm{~N}) / 7
$$

where $A$ is alkali digestion value; $G$ is grade of each grain; and $N$ is number of grains at the same degree.

Selenium $(\mathrm{Se})$ was measured in finely ground foxtail millet grain $(500 \mathrm{mg})$ was acid-digested with $5 \mathrm{~mL} 70 \%$ superior-grade pure nitric acid and $2 \mathrm{~mL} \mathrm{30 \%} \mathrm{hydrogen}$ peroxide. The digested samples were diluted to $25 \mathrm{~mL}$ with ultrapure water $\left(18.2 \mathrm{M} \Omega \mathrm{cm}^{-1}\right)$. Se concentration in the digestion solution was analyzed by atomic fluorescence spectrometry.

Folic acid was determined in exactly $2.5 \mathrm{~g}$ foxtail millet grain sample was weighed into $25 \mathrm{~mL} 0.1 \mathrm{~mol} \mathrm{~L}^{-1}$ potassium dihydrogen phosphate and incubated in a $50{ }^{\circ} \mathrm{C}$ thermostat water bath for $8 \mathrm{~h}$. The sample was centrifuged in a high-speed refrigerated centrifuge at $5000 \mathrm{rpm}$ for $10 \mathrm{~min}$. The supernatant was collected, followed by the addition of $0.5 \mathrm{~g}$ aniline-treated activated $\mathrm{C}$. The mixture was thoroughly vortexed and then heated to boiling in a water bath for $10 \mathrm{~min}$. The sample was filtered and the supernatant was discarded. The residue was washed five times with $7 \mathrm{~mL} \mathrm{3 \%}$ ammonia: $70 \%$ ethanol. The eluate was evaporated and concentrated to $5 \mathrm{~mL}$, followed by addition of $1 \mathrm{~mL} \mathrm{2 \%}$ glacial acetic acid. Thereafter, $0.04 \%$ potassium permanganate was added dropwise until the color of the solution no longer changed. Furthermore, 3\% hydrogen peroxide was added until the color of potassium permanganate faded. The solution was diluted to a volume of $10 \mathrm{~mL}$. The fluorescence intensity was measured using a fluorescence spectrophotometer at $\mathrm{Ex}=370 \mathrm{~nm}$ and $\mathrm{Em}=$ $443 \mathrm{~nm}$ (Shao et al., 2014).

The content of grain yellow pigment was determined using the method described by Ning et al. (2016). The absorbance was measured at $450 \mathrm{~nm}$ using a spectrophotometer.

\section{Statistical analysis}

All experiments were performed at least in triplicate and results presented as mean values. Mean values of grain quality indicators were compared by a one-way ANOVA, and Duncan's test was used to determine the significant differences among the treatments. Principal component analysis (PCA), Gray relational analysis (GRA), multivariate stepwise regression analysis (SRA), and path analysis (PA) were conducted with comprehensive quality of foxtail millet as the parent factor and environmental factors as the sub-factors. We used $P=0.05$ as the statistical significance thresholds. Data were statistically analyzed using Statistics Analysis System 8.0.

\section{RESULTS}

\section{Regional difference in grain quality indicator levels and correlation analysis with environmental factors}

Grain quality of foxtail millet significantly varied among different locations $(P<0.05$; Figure 1$)$. The grain content of protein at Gaoping, fat at Fanshi, alkali digestion value at Fanshi, gel consistency at Qinxian, yellow pigment at Gaoping, folic acid at Qinxian and Se at Qinxian were significantly higher than those at the other locations. Grain amylose content was lowest at Qinxian. Compared with the above locations, protein at Fenyang, fat at Yuci, alkali

Table 3. Standard for alkali digestion value of foxtail millet grain samples.

\begin{tabular}{|c|c|c|}
\hline Standard & Degree of decomposition & Definition \\
\hline 1 & Grain unchanged & White core in grain \\
\hline 2 & Grain expanded & White core in grain, with powdery ring \\
\hline 3 & Grain expanded, with incomplete or narrow ring & White core in grain, with flocculent or nebulous ring \\
\hline 4 & Grain enlarged, with complete and wide ring & Cotton white core in grain, with nebulous ring \\
\hline 5 & Grain cracked, with complete and wide ring & Cotton white core in grain, with clear ring \\
\hline 6 & Grain partially dispersed and dissolved, blended with ring & Cloud white core in grain, with no ring \\
\hline 7 & Grain completely dispersed & Both core and ring disappeared in grain \\
\hline
\end{tabular}


Figure 1. Grain quality indicator levels of foxtail millet 'Changnong 35' at five different locations in Shanxi Province, China.
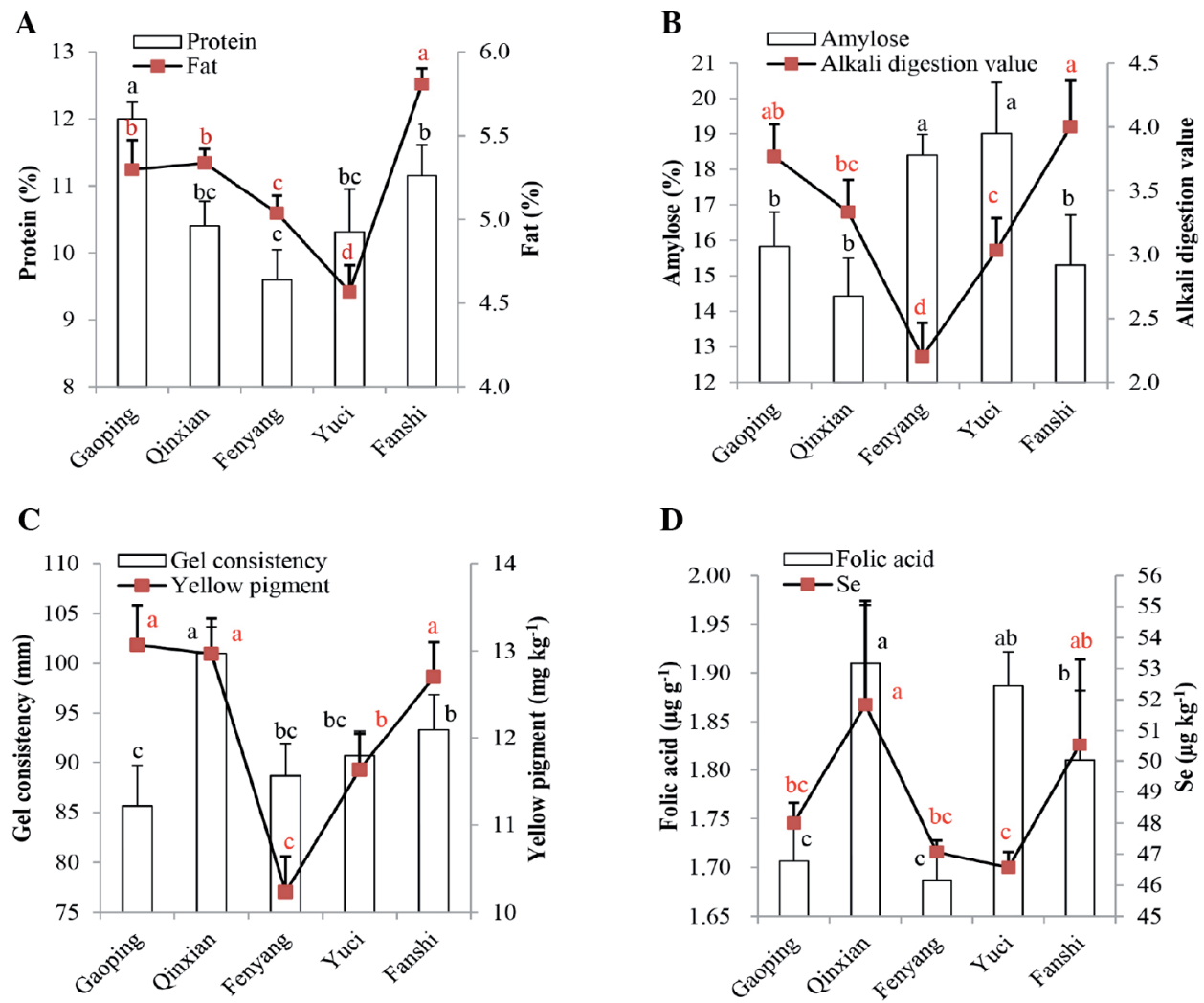

Five different locations

Values represent the means and vertical bars indicate the standard deviation of three separate experiments. Different letters on histograms or line graphs indicate significant differences according to Duncan's test $(P<0.05)$.

digestion value at Fenyang, gel consistency at Gaoping, yellow pigment at Fenyang, folic acid at Fenyang and Se at Yuci were reduced by $20.0 \%, 21.3 \%, 45.0 \%, 14.9 \%, 21.7 \%$, $11.5 \%$, and $10.2 \%$, respectively. Amylose content at Yuci was $31.7 \%$ higher compared to Qinxian.

Nonsignificant correlation was found between protein, amylase, alkali digestion value, gel consistency, yellow pigment, folic acid content and environmental factors. Nonetheless, there were significant correlations between fat and altitude. Se was significantly or highly significantly correlated with sunshine hours, altitude, and $\geq 20{ }^{\circ} \mathrm{C}$ accumulated temperature (Table 4).

\section{PCA of grain quality indicators of foxtail millet}

From the above analyses, we found changes in foxtail millet grain quality were dependent on location and climatic factors. To further analyze the relationship between the grain quality of foxtail millet and the environmental factors, PCA was used. Only two eigenvalues were $>1$ and explained $85.18 \%$ of the total variance in grain quality (Table 5). The first two eigenvalues were therefore selected for further analysis; other small but non-zero eigenvalues were discarded to establish a probable number of contributing source factors. It was evident from the rotated component matrix that all quality parameters were explained by the

Table 4. Correlation coefficients between grain quality of foxtail millet and environmental factors at five different locations in Shanxi Province, China.

\begin{tabular}{|c|c|c|c|c|c|c|c|c|}
\hline Factors & Protein & Fat & Amylose & $\begin{array}{l}\text { Alkali } \\
\text { digestion } \\
\text { value }\end{array}$ & $\begin{array}{c}\text { Gel } \\
\text { consistency }\end{array}$ & $\begin{array}{c}\text { Yellow } \\
\text { pigment }\end{array}$ & $\begin{array}{l}\text { Folic } \\
\text { acid }\end{array}$ & $\mathrm{Se}$ \\
\hline Sunshine hours & 0.03 & -0.79 & 0.77 & -0.19 & -0.6 & -0.28 & -0.01 & $-0.85^{*}$ \\
\hline Precipitation & 0.41 & 0.15 & -0.68 & 0.4 & 0.47 & 0.74 & 0.38 & 0.55 \\
\hline Altitude & 0.37 & $0.83 *$ & -0.79 & 0.76 & 0.56 & 0.67 & 0.41 & $0.86^{*}$ \\
\hline Latitude & -0.2 & 0.35 & 0.04 & 0.18 & 0.19 & -0.13 & 0.24 & 0.2 \\
\hline$\geq 20^{\circ} \mathrm{C}$ accumulated temperature & -0.12 & -0.74 & 0.8 & -0.54 & -0.79 & -0.57 & -0.52 & $-0.96 * *$ \\
\hline Diurnal temperature range & -0.65 & -0.11 & -0.15 & -0.57 & 0.62 & -0.25 & 0.19 & 0.34 \\
\hline
\end{tabular}

\footnotetext{
*,**Significant at the 0.05 and 0.01 probability levels, respectively.
} 
Table 5. Eigenvalues, contribution, and cumulative contribution of the correlation matrix of indicators for grain quality of foxtail millet.

\begin{tabular}{lccr}
\hline $\begin{array}{l}\text { Principal } \\
\text { component }\end{array}$ & Eigenvalue & $\begin{array}{c}\text { Contribution } \\
\text { proportion }(\%)\end{array}$ & $\begin{array}{c}\text { Cumulative } \\
(\%)\end{array}$ \\
\hline F1 & 4.6574 & 58.2172 & 58.2172 \\
F2 & 2.1569 & 26.9609 & 85.1781 \\
F3 & 0.9990 & 12.4871 & 97.6652 \\
F4 & 0.1868 & 2.3348 & 100.0000 \\
\hline
\end{tabular}

first two principal components (Table 6). The first principal component (PC1) explained $58.22 \%$ of the variance including fat, amylase, alkali digestion value, yellow pigment, and Se. The second principal component (PC2) accounted for $26.96 \%$ of the variance and had high loadings for protein, gel consistency, and folic acid. Consequently, PC1 was chosen to represent the comprehensive quality of foxtail millet.

GRA between comprehensive quality of foxtail millet and environmental factors

The grey relational grade (GRG) between comprehensive quality of foxtail millet and environmental factors during the growing season (May-September) are shown in Table 7. Altitude $(\mathrm{GRG}=0.8137)$ showed the greatest effect on grain quality, followed by precipitation $(\mathrm{GRG}=0.7744)$, diurnal temperature range $(\mathrm{GRG}=0.6816)$, latitude $(\mathrm{GRG}$

Table 6. Eigenvectors of selected principal components for grain quality of foxtail millet.

\begin{tabular}{lcc}
\hline & \multicolumn{2}{c}{ Eigenvector } \\
\cline { 2 - 3 } Quality indexes & $\mathrm{F} 1$ & $\mathrm{~F} 2$ \\
\hline Protein & 0.2924 & -0.4880 \\
Fat & 0.3613 & -0.1460 \\
Amylose & -0.4409 & -0.0190 \\
Alkali value & 0.4006 & -0.2417 \\
Gel consistency & 0.2353 & 0.5843 \\
Yellow pigment & 0.4263 & -0.1081 \\
Folic acid & 0.1653 & 0.5069 \\
Se & 0.4058 & 0.2678 \\
\hline
\end{tabular}

Table 7. Grey relational grade and rank between comprehensive quality of foxtail millet and environmental factors during the growing season (May-September).

\begin{tabular}{lcc}
\hline Factors & Grey relational grade & Rank \\
\hline Sunshine hours & 0.5052 & 5 \\
Precipitation & 0.7744 & 2 \\
Altitude & 0.8137 & 1 \\
Latitude & 0.5417 & 4 \\
$\geq 20^{\circ} \mathrm{C}$ accumulated temperature & 0.4517 & 6 \\
Diurnal temperature range & 0.6816 & 3 \\
\hline
\end{tabular}

$=0.5417)$, sunshine hours $(\mathrm{GRG}=0.5052)$, and $\geq 20{ }^{\circ} \mathrm{C}$ accumulated temperature $(\mathrm{GRG}=0.4517)$.

The GRG between grain quality of foxtail millet and climate factors at different growth stages was N3 $>$ N20 $>$ $\mathrm{N} 19>\mathrm{N} 18>\mathrm{N} 10>\mathrm{N} 1>\mathrm{N} 4>\mathrm{N} 2>\mathrm{N} 17>\mathrm{N} 6>\mathrm{N} 8>\mathrm{N} 11$ $>\mathrm{N} 16>\mathrm{N} 5>\mathrm{N} 7>\mathrm{N} 9>\mathrm{N} 13>\mathrm{N} 12>\mathrm{N} 14>\mathrm{N} 15$ (Table 8). The results showed that precipitation of July (booting-heading stage) had the greatest effect on grain quality, followed by diurnal temperature range of September (the middle and late stage of filling), August (filling stage), and July (bootingheading stage), and sunshine hours of September (middle and late stage of filling). The $\geq 20{ }^{\circ} \mathrm{C}$ accumulated temperature had the least effect on grain quality.

SRA and PA between environmental factors and comprehensive quality of foxtail millet

To identify the real regulatory role of environmental factors on grain quality of foxtail millet, SRA was conducted. The comprehensive quality of foxtail millet collected at different locations was used as the dependent variable $\mathrm{Y}$, and the environmental factors during the growing season of foxtail millet were used as the independent variables, including sunshine hours (X1), precipitation (X2), altitude (X3), latitude (X4), $\geq 20{ }^{\circ} \mathrm{C}$ accumulated temperature (X5), and diurnal temperature range (X6). The following multivariate equation was obtained:

$$
\mathrm{Y}=48.1673296+0.016169940249 \mathrm{X} 2+
$$$$
0.005827128145 \mathrm{X} 3-0.006118129710 \mathrm{X} 5\left(\mathrm{R}^{2}=0.99, P=\right.
$$$$
0.0048 \text {, Durbin-Watson }=2.8 \text { ). }
$$

As shown in regressive equation, precipitation, altitude, and $\geq 20{ }^{\circ} \mathrm{C}$ accumulated temperature remained in the final model, explaining $99 \%$ of total variance in grain quality. Considering the positive and significant regression coefficients of precipitation and altitude, we could conclude that increasing the level of these factors would improve the quality. Regarding the negative and significant regression coefficient of $\geq 20{ }^{\circ} \mathrm{C}$ accumulated temperature, we could conclude that increasing the level of this factor would reduce the grain quality.

To further determine the direct and indirect effects of the three major environmental factors identified by SRA, we performed PA between precipitation (X2), altitude (X3), $\geq 20{ }^{\circ} \mathrm{C}$ accumulated temperature (X5), and grain quality of foxtail millet. The results (Table 9) showed that direct effects of the independent variables $\mathrm{X} 2, \mathrm{X} 3$, and $\mathrm{X} 5$ were: $\mathrm{P} 2 \mathrm{Y}=0.4383, \mathrm{P} 3 \mathrm{Y}=0.2747$, and $\mathrm{P} 5 \mathrm{Y}=$ -0.5147 , respectively; the absolute value ranked IP5YI $>|\mathrm{P} 2 \mathrm{Y}|>|\mathrm{P} 3 \mathrm{Y}|$. This indicates that the direct effects of $\geq 20{ }^{\circ} \mathrm{C}$ accumulated temperature (X5), precipitation

Table 8. Grey relational analysis between comprehensive quality of foxtail millet and climate factors at different growth stages.

\begin{tabular}{|c|c|c|c|c|c|}
\hline \multirow[b]{2}{*}{ Climate factors } & \multicolumn{5}{|c|}{ Grey relational grade at different growth stages } \\
\hline & May & June & July & August & September \\
\hline Precipitation & $0.6668(\mathrm{~N} 1)$ & $0.6377(\mathrm{~N} 2)$ & $0.7746(\mathrm{~N} 3)$ & $0.6426(\mathrm{~N} 4)$ & $0.5466(\mathrm{~N} 5)$ \\
\hline Sunshine hours & 0.6037 (N6) & $0.5257(\mathrm{~N} 7)$ & $0.5895(\mathrm{~N} 8)$ & 0.5146 (N9) & $0.6691(\mathrm{~N} 10)$ \\
\hline$\geq 20^{\circ} \mathrm{C}$ accumulated temperature & $0.558(\mathrm{~N} 11)$ & $0.501(\mathrm{~N} 12)$ & $0.5013(\mathrm{~N} 13)$ & $0.501(\mathrm{~N} 14)$ & $0.4958(\mathrm{~N} 15)$ \\
\hline Diurnal temperature range & $0.5518(\mathrm{~N} 16)$ & $0.6061(\mathrm{~N} 17)$ & $0.6778(\mathrm{~N} 18)$ & $0.7026(\mathrm{~N} 19)$ & $0.7503(\mathrm{~N} 20)$ \\
\hline
\end{tabular}


Table 9. Path analysis between comprehensive quality of foxtail millet and environmental factors during the growing season (May-September).

\begin{tabular}{cc}
\hline Independent variable & Direct path coefficient (Direct action) \\
\hline X2 & 0.4383 \\
X3 & 0.2747 \\
X5 & -0.5147 \\
\hline
\end{tabular}

$\mathrm{X}$ 2: Precipitation; $\mathrm{X}$ 3: altitude; $\mathrm{X} 5: \geq 20^{\circ} \mathrm{C}$ accumulated temperature.

(X2), and altitude (X3) on grain quality of foxtail millet (Y) declined sequentially. Additionally, the path coefficient between precipitation (X2) or altitude (X3) and grain quality of foxtail millet $(\mathrm{Y})$ was positive and showed a highly significant positive correlation. On the contrary, the direct path coefficient between $\geq 20{ }^{\circ} \mathrm{C}$ accumulated temperature (X5) and grain quality of foxtail millet (Y) was negative and showed a highly significant negative correlation. This indicates that during the growing season of foxtail millet, increase of precipitation and altitude had a major positive effect, while $\geq 20^{\circ} \mathrm{C}$ accumulated temperature had a major negative effect on grain quality of foxtail millet.

\section{DISCUSSION}

Environmental conditions have important effects on grain quality of foxtail millet. Existing studies on the relationship between grain quality of foxtail millet and environmental factors have commonly used simple correlation analysis, which cannot reveal the relationship of internal regulation (He et al., 1985; Li, 1987; Zhao et al., 2002). Here, we adopted multiple statistical analyses to progressively reveal the environmental factors affecting grain quality of foxtail millet.

In this study, both the quality indicators of foxtail millet and environmental factors were multiple variables. The results of ANOVA and simple correlation analysis (Figure 1, Table 4) showed a lack of consistency for grain quality indicator levels of foxtail millet across different locations. Meanwhile, the same environmental factors showed varying effects on different grain quality indicators of foxtail millet, which showed a certain complexity. Thus, it was difficult to find common environmental factors affecting grain quality of foxtail millet. In this case, PCA was first used to obtain the principal component representing the comprehensive quality of foxtail millet. Furthermore, the key environmental factors affecting grain quality of foxtail millet were obtained and an optimal relationship model was established by SRA. Meanwhile, PA was used to further reveal the direct and indirect effects of major environmental factors and thereby clarify their regulatory role in grain quality of foxtail millet. The progressive system analysis based on the above methods is also a quantitative comparative analysis of the development trend in the system dynamic process. This approach avoids the disadvantages of single indicators and methods, few and scattered environmental factors, and lack of comprehensive analysis and evaluation in the analysis of the relationship between the crop and the environment. Thus, the conclusions are more reliable and can reflect the objective, actual conditions, which conform to the needs of this study. Moreover, the results provide a more comprehensive and improved decision-making basis for the study and analysis of follow-up problems.

Grain quality of foxtail millet is a comprehensive trait, including nutritional quality as well as cooking and eating quality (Suman et al., 2015). In the present study, based on the results of PCA, we selected PC1 which contributed to $58.22 \%$ of the total variance to represent the comprehensive quality of foxtail millet. This component included both nutritional quality (fat, yellow pigment, and Se) and cooking and eating quality (amylase, alkali digestion value), and thus could fully reflect the quality of foxtail millet.

The GRA between environmental factors during the growing season and PC1 revealed that altitude had the greatest effect on grain quality of foxtail millet. The altitude difference is a comprehensive manifestation of the differences in various meteorological factors, as altitude is significantly correlated with meteorological factors such as diurnal temperature difference, sunshine hours, latitude, and precipitation (Shao et al., 2014). In the process of quality formation, a higher altitude is more conducive to the accumulation and transformation of nutrients, further contributing to the accumulation of secondary metabolites (Decazy et al., 2003; Alice et al., 2016). Zhao et al. (1990) found that altitude played a decisive role in grain quality of foxtail millet in a study of 10 ecological sites from the National Foxtail Millet Ecological Joint Test (south to north: Harbin, Gongzhuling, Chaoyang, Hohhot, Jinzhou, Chengde, Changzhi, Jinan, Zhengzhou, and Lueyang). With increasing altitude, grain protein and fat content of foxtail millet increased, while grain starch content showed the opposite trend. Zhao et al. (2002) found that higher altitude and greater diurnal temperature difference were more favorable for the formation of high-quality foxtail millet in a study of different ecological zones in Hainan, Shaanxi, Hebei, and Shanxi Provinces, China. There have been numerous reports regarding the effect of altitude on the quality of crops. For instance, the oil content of chia planted at high altitude is significantly higher than that of chia planted at low altitude (Baginsky et al., 2016). Coffees at higher altitudes produced with better sensory quality (Alice et al., 2016). Altitude not only affects the quality of crops, but also significantly influences yield. It has been reported that wheat yields increase with increasing altitude (Xiao et al., 2008).

Another major environmental factor that affected grain quality of foxtail millet was precipitation. At different growth stages, precipitation of July (booting-heading stage) showed the greatest effect on the grain quality of foxtail millet. This stage is the most water-consuming period of foxtail millet, when the fructification organ of foxtail millet is completely developed and ready to be filled. In this stage, if there is sufficient water and smooth transport of nutrients, the ear node will quickly extend the flag leaf and the ear can be fully developed, which is conducive to the formation 
of high-quality foxtail millet with high protein and fat content (Zhao et al., 2002). The precipitation at the other growth stages had less effect on the grain quality of foxtail millet. Diurnal temperature range was also an important environmental factor affecting grain quality of foxtail millet. At different growth stages, the diurnal temperature range of July-September (booting, heading, and grain filling stages) showed greater effects on the grain quality of foxtail millet. This period is critical for the formation of grain quality of foxtail millet, when a large diurnal temperature range is conducive to the formation and accumulation of starch, fat, protein and other nutrients in the grain of foxtail millet. Owing to warmer daytime temperatures, photosynthetic enzyme activity increases in crops, leading to an enhancement of photosynthesis. The temperature is relatively low at nighttime, therefore the respiratory enzyme activity decreases and respiration is attenuated. This results in higher synthesis and lower consumption, which favors the formation, accumulation, and transformation of nutrients in crop grains, thereby contributing to the accumulation of secondary metabolites (Zhao and Li, 2005; Li et al., 2011). The following factor was sunshine hours. At different growth stages, the sunshine hours of June and August (jointing and grain filling stages) had the greatest effect on grain quality of foxtail millet. In the filling stage, the crop mainly stores photosynthesis-produced starch, protein and accumulated organic matter in the grains through assimilation using light. The effect of accumulated temperature on grain quality of foxtail millet was less than those of precipitation, diurnal temperature range, and sunshine hours. Grain quality of foxtail millet had generally low GRG to accumulated temperature at different growth stages of foxtail millet.

The results of SRA and PA between environmental factors and PC1 showed that altitude and precipitation during the growing season of foxtail millet (May-September) were the major environmental factors affecting grain quality of foxtail millet. These two factors had direct positive effects on the grain quality; namely, the higher the altitude and precipitation, the better the grain quality of foxtail millet. On the contrary, $\geq 20{ }^{\circ} \mathrm{C}$ accumulated temperature showed direct negative effect on the grain quality; namely, the higher the $\geq 20^{\circ} \mathrm{C}$ accumulated temperature, the worse the grain quality. The negative effect of accumulated temperature on grain quality of foxtail millet is mainly due to a decline in accumulated temperature during the late growth stages. Therefore, respiration and the consumption of organic matter are reduced, which contributes to the accumulation, transportation, and transformation of photosynthetic products. In practice, we can substitute the environmental factors in the planting area of foxtail millet into the equation $\left(P=0.0048, \mathrm{R}^{2}=0.99\right)$ to obtain the grain comprehensive quality of foxtail millet, guide the design of production environment module for high-quality foxtail millet, and provide a basis for digital production of highquality foxtail millet.

\section{CONCLUSIONS}

The effect of environmental factors on grain quality of foxtail millet is not simple, but the result of a combination of factors. When selecting the location for cultivation of foxtail millet, full consideration should be given to altitude, precipitation in July and $\geq 20{ }^{\circ} \mathrm{C}$ accumulated temperature in the region. Altitude, precipitation had direct positive effects on the grain quality. On the contrary, $\geq 20{ }^{\circ} \mathrm{C}$ accumulated temperature showed direct negative effect on the grain quality. The regression equation proposed in this study $\left(P=0.0048, \mathrm{R}^{2}=0.99\right)$ can be used to predict and forecast grain quality of foxtail millet.

\section{ACKNOWLEDGEMENTS}

This work was supported by the National Natural Science Foundation of China (31301269); Science and Technology Development Project of Universities in Shanxi Province (2014149); Agricultural Scientific and Technological Research Project in Shanxi Province, China (201403110063); Scientific and Technological Project of Shanxi Province (20150311016-2); Key Scientific and Technological Project of Shanxi Province (2015-TN-09).

\section{REFERENCES}

Adrian, M.I.R. 2012. Comparison of regression methods for phenology. International Journal of Biometeorology 56:707-717. Alice, D.S.S., Pinheiro, A.C.T., Ferreira, W.P.M., Silva, L.J.D., Rufino, J.L.D.S., and Sakiyama, N.S. 2016. Sensory analysis of specialty coffee from different environmental conditions in the region of Matas de Minas, Minas Gerais, Brazil. Revista Ceres 63:436-443.

American Association of Cereal Chemists. 2000. AACC International approved methods. $9^{\text {th }}$ ed. American Association of Cereal Chemists (AACC) International, St. Paul, Minnesota, USA.

Anju, M., and Banerjee, D.K. 2012. Multivariate statistical analysis of heavy metals in soils of a $\mathrm{Pb}-\mathrm{Zn}$ mining area, India. Environmental Monitoring and Assessment 184:4191-4206.

AOAC. 2000. Official methods of analysis. $17^{\text {th }}$ ed. Association of Official Analytical Chemists (AOAC), Gaithersburg, Maryland, USA.

Baginsky, C., Arenas, J., Escobar, H., Garrido, M., Valero, N., Tello, D., et al. 2016. Growth and yield of chia (Salvia hispanica L.) in the Mediterranean and desert climates of Chile. Chilean Journal of Agricultural Research 76:255-264.

Bornhofen, E., Benin, G., Storck, L., Marchioro, V., Meneguzzi, C., Milioli, A., et al. 2017. Environmental effect on genetic gains and its impact on bread-making quality traits in Brazilian spring wheat. Chilean Journal of Agricultural Research 77:27-34.

Chen, L., Tang, L., Shi, P.H., Yang, B.H., Sun, T., Cao, W.X., et al. 2017. Effects of short-term high temperature on grain quality and starch granules of rice (Oryza sativa L.) at post-anthesis stage. Protoplasma 254:935-943.

Decazy, F., Avelino, J., Guyo, B., Perriot, J.J., Pineda, C., and Cilas, C. 2003. Quality of different Honduran coffees in relation to several environments. Journal of Food Science 68:2356-2361. 
Diao, X.M., Schnable, J., Bennetzen, J.L., and Li, J.Y. 2014. Initiation of Setaria as a model plant. Frontiers of Agricultural Science and Engineering 21:16-20.

Donoso-Ñanculao, G., Paredes, M., Becerra, V., Arrepol, C., and Balzarini, M. 2016. GGE biplot analysis of multi-environment yield trials of rice produced in a temperate climate. Chilean Journal of Agricultural Research 76:152-157.

Farrell, A.D., and Gilliland, T.J. 2011. Yield and quality of forage maize grown under marginal climatic conditions in Northern Ireland. Grass and Forage Science 66:214-223.

Hao, Z.W., Fan, X.H., Zhu, X.Q., Ma, J.P., and Wang, M.B. 2009. Change trends of sunshine duration over the 50 years from 1959 to 2008 in Shanxi province, China. Ecology and Environment 18:1807-1811 (Chinese with English abstract).

He, W.X., Wang, W.Z., and Wang, H.L. 1985. Study on protein content of foxtail millet Landraces Originated from North China. China Seeds 3:19-21 (Chinese with English abstract).

Huang, J.C. 2011. Application of grey system theory in telecare. Computers in Biology and Medicine 41:302-306.

Jones, M.K., and Liu, X. 2009. Origins of agriculture in East Asia. Science 324:730-731.

Li, X.Z. 1987. The results of analyses of protein and fat contents in millet local varieties from Jilin province. Journal of Jilin Agricultural Sciences 1:24-27 (Chinese with English abstract).

Li, H.X., Chen, Z., Hu, M.X., Wang, Z.M., Hua, H., Yin, C.X., et al. 2011. Different effects of night versus day high temperature on rice quality and accumulation profiling of rice grain proteins during grain filling. Plant Cell Reports 30:1641-1659.

Lu, D.L., Yang, H., Shen, X., and Lu, W.P. 2016. Effects of high temperature during grain filling on physicochemical properties of waxy maize starch. Journal of Integrative Agriculture 15:309-316.

Marketta, S. 2008. Effects of environmental factors on grain yield and quality of oats (Avena sativa L.) cultivated in Finland. Acta Agriculturae Scandinavica Section B-Soil and Plant Science 48:129-137.

Mostafa, A., Ali, N., Hossein, S., and Saeed, A. 2011. Correlated response of morpho-physiological traits of grain yield in durum wheat under normal irrigation and drought stress conditions in greenhouse. African Journal of Biotechnology 10:19771-19779.

Muthamilarasan, M., and Prasad, M. 2015. Advances in Setaria genomics for genetic improvement of cereals and bioenergy grasses. Theoretical and Applied Genetics 128:1-14.

National Bureau of Statistics of China. 2013. China statistical yearbook. China Statistics Press, Beijing, China.

Ning, N., Yuan, X.Y., Dong, S.Q., Wen, Y.Y., Gao, Z.P., Guo, M.J., et al. 2016. Increasing selenium and yellow pigment concentrations in foxtail millet (Setaria italica L.) grain with foliar application of Selenite. Biological Trace Element Research 170:245-252.
Qian, J.X., and Hu, L.W. 2008. Analysis of climatic resources utilization efficiency of maize in Shanxi province. Journal of Maize Sciences 16:192-195 (Chinese with English abstract).

Shao, L.H., Wang, L., Bai, W.W., and Liu, Y.J. 2014. Evaluation and analysis of folic acid content in millet from different ecological regions in Shanxi province. Journal of Integrative Agriculture 47:1265-1272 (Chinese with English abstract).

Suman, V., Sarita, S., and Neha, T. 2015. Comparative study on nutritional and sensory quality of barnyard and foxtail millet food products with traditional rice products. Food Science and Technology Research 52:5147-5155.

Tran, N.A., Daygon, V.D., Resurreccion, A.P., Cuevas, R.P., Corpuz, H.M., and Fitzgerald, M.A. 2011. A single nucleotide polymorphism in the Waxy gene explains a significant component of gel consistency. Theoretical and Applied Genetics 123:519-525.

Ullah, A., Ahmad, A., Khaliq, T., and Akhtar, J. 2017. Recognizing production options for pearl millet in Pakistan under changing climate scenarios. Journal of Integrative Agriculture 16:762-773.

Veeranagamallaiah, G., Jyothsnakumari, G., Thippeswamy, M., Chandra Obul Reddy, P., Surabhi, G.K., Sriranganayakulu, G., et al. 2008. Proteomic analysis of salt stress responses in foxtail millet (Setaria italica L. cv. Prasad) seedlings. Plant Science 175:631-641.

Xiao, G.J., Zhang, Q., Yao, Y.B., Zhao, H., Wang, R.Y., Bai, H.Z., et al. 2008. Impact of recent climatic change on the yield of winter wheat at low and high altitudes in Semi-Arid Northwestern China. Agriculture Ecosystems and Environment 127:37-42.

Yang, X.Y., Wan, Z.W., Perry, L., Lu, H.Y., Wang, Q., Zhao, C.H., et al. 2012. Early millet use in northern China. Proceedings of the National Academy of Sciences of the United States of America 109:3726-3730.

Zhao, H.Y., Chen, J.F., Wang, H.L., Yang, C.Y., and Wang, J.H. 2002. Effect of different ecological environment on quality in high-quality millet. Chinese Journal of Eco-Agriculture 10:6567 (Chinese with English abstract).

Zhao, X.L., and Li, W.X. 2005. Effect of the nitrogen and phosphorus levels and meteorological conditions on formation dynamics of grain protein content in spring wheat. Acta Physica Sinica 25:1914-1920.

Zhao, S.L., Li, H., Wang, D.Y., Guo, G.L., and Wang, Y.W. 1990. The effects of ecological environment on contents of protein, fat and starch of millet. Acta Agriculturae Boreali-Sinica 5:48-53 (Chinese with English abstract). 